\title{
A Response to "Healthcare Workers' Emotions, Stressor Experiences and Coping Strategies During the COVID-19 Pandemic in Vietnam" [Letter]
}

\section{Aanchal Gupta \\ Roshan Jonash Raymond}

Barts and The London School of Medicine and Dentistry, London, UK
Correspondence: Aanchal Gupta Barts and The London School of Medicine and Dentistry, Garrod Building, Turner Street, Whitechapel, London, EI 2AD, UK Tel +447946769695

Email a.gupta@smdl6.qmul.ac.uk

\section{Dear editor}

We read, with great interest the paper by Thai et al addressing Healthcare Worker's emotions, experiences and coping strategies during the COVID-19 pandemic. ${ }^{1} \mathrm{We}$ worked as intensive care healthcare assistants, vaccinators and virtual visit coordinators, alongside attending clinical placements for our medical degree throughout the second wave in the UK. We understand the psychological and physical burden of the pandemic. As such, we would like to offer our perspectives on the challenges we have experienced and recommendations on the Study.

The Study had $71.1 \%$ female participants, a percentage which appears to be chosen out of convenience. It would have been appropriate to get an equal number of men and women as a study by Liu et al has shown that female healthcare workers are more vulnerable to mental health problems due to the COVID-19 outbreak. ${ }^{2}$ Moreover, having an understanding of the baseline stress level of the participants before the pandemic may aid in deducing whether the the pandemic has caused a significant increase in stress levels. Table 2 addresses work related stressors, however, participants could have been asked whether they were undergoing any personal stresses in their lives which may already be impacting their mental health. Similarly, the authors report $71.2 \%$ of participants felt stress when learning of new cases of COVID-19 on the news and Riehm et al have shown that a greater amount of time spent on social media and traditional media to learn about COVID-19 is associated with increased mental distress. ${ }^{3}$ Approaching the participants holistically and learning of their external contributors to stress is important in this study.

In "Table 3", there are a number of coping strategies used by staff. It may have been pertinent to use an open-ended question rather than providing options as coping strategies are often personal and can be niche. A study has shown that in patient groups, open-ended questions are positively associated with anxiety disclosure. ${ }^{4}$ Additionally, the authors have provided the option of seeking help from a family doctor or other doctor, however, this could have been rephrased to "professional help", as this includes helplines and psychologists, amongst other services. It is insightful to read the emotions of the healthcare workers towards the beginning of the pandemic. However, as the participants were from a hospital where there were no recorded COVID-19 cases, conducting another study at a later stage when there are cases, may be useful. The first study can give the 
anticipatory stressors and prevention strategies, whereas the latter may provide insight into the stressors of caring for COVID-19 patients. The two scenarios may reveal different psychological support needs.

In conclusion, the mental health of healthcare staff during a pandemic is a multi-dimensional subject. Conducting studies such as this highlight the severity of the issue and provoke conversations to address these challenges. Finding specific and frequently reported issues will aid in providing targeted services for healthcare staff.

\section{Disclosure}

The authors report no conflicts of interest in this communication.

\section{References}

1. Thai TT, Nguyen TH, Pham PTT, Bui HHT, Bui TNM. Healthcare workers' emotions, stressor experiences and coping strategies during the COVID-19 pandemic in Vietnam. Risk Manag Healthc Policy. 2021;14:4281-4291. doi:10.2147/RMHP.S322929

2. Liu S, Yang L, Zhang C, et al. Gender differences in mental health problems of healthcare workers during the coronavirus disease 2019 outbreak. J Psychiatr Res. 2021;137:393-400. PMID: 33765451; PMCID: PMC7962932. doi:10.1016/j.jpsychires.2021.03.014

3. Goto M, Takemura YC. Which medical interview skills are associated with patients' verbal indications of undisclosed feelings of anxiety and depressive feelings? Asia Pac Fam Med. 2016;15:2. PMID: 26924940; PMCID: PMC4769835. doi:10.1186/s12930-0160027-x

4. Riehm KE, Holingue C, Kalb LG, et al. Associations between media exposure and mental distress among U.S. adults at the beginning of the COVID-19 pandemic. Am J Prev Med. 2020;59(5):630-638. PMID: 33011008; PMCID: PMC7351429. doi:10.1016/j.amepre.2020.06.008

Dove Medical Press encourages responsible, free and frank academic debate. The content of the Risk Management and Healthcare Policy 'letters to the editor' section does not necessarily represent the views of Dove Medical Press, its officers, agents, employees, related entities or the Risk Management and Healthcare Policy editors. While all reasonable steps have been taken to confirm the content of each letter, Dove Medical Press accepts no liability in respect of the content of any letter, nor is it responsible for the content and accuracy of any letter to the editor.

\section{Publish your work in this journal}

Risk Management and Healthcare Policy is an international, peerreviewed, open access journal focusing on all aspects of public health, policy, and preventative measures to promote good health and improve morbidity and mortality in the population. The journal welcomes submitted papers covering original research, basic science, clinical \& epidemiological studies, reviews and evaluations, guidelines, expert opinion and commentary, case reports and extended reports. The manuscript management system is completely online and includes a very quick and fair peer-review system, which is all easy to use. Visit http://www.dovepress.com/testimonials.php to read real quotes from published authors. 